\title{
RELAÇÕES DE IDENTIDADE DOCENTE: TEARES E DIÁLOGOS ENTRE PROFESSORES E FORMADORES EM SEUS PERCURSOS E ESPAÇOS FORMATIVOS
}

\author{
TEACHING IDENTITY RELATIONS: TEARS AND DIALOGUES BETWEEN TEACHERS \\ AND TRAINERS IN THEIR TRAILS AND TRAINING SPACES
}

\begin{abstract}
Mônica Ramos da Costa Macedo
Possui especialização em Produção do Conhecimento na Escola Básica: Da Pré-Escola à $4^{a}$ série pela Universidade Federal Fluminense e pela CEFET-RJ em Relações Etnicorraciais e Educação. É graduada em Pedagogia pelo Centro de Ciências Humanas e Sociais Instituto Isabel. Atualmente, trabalha na Secretaria Municipal de Educação do Rio de Janeiro. Tem experiência na área de Educação e na formação de professores, com ênfase em alfabetização. Rio de Janeiro/RJ - Brasil. m_macedo2006@yahoo.com.br
\end{abstract}

Sabrina Guedes de Oliveira

Mestre pela UNICARIOCA em Novas Tecnologias Digitais na Educação. Possui Especialização em Mídias Educativas, Psicopedagogia, Gestão Escolar e Coordenação Pedagógica. Graduada em História pela Universidade Federal do Estado do Rio de Janeiro (2014) e graduação em Pedagogia pela Universidade do Estado do Rio de Janeiro (2002). Atualmente é estatutário da Prefeitura da Cidade do Rio de Janeiro. Tem experiência na área de Educação, com ênfase em Tecnologia Educacional Digital, Alfabetização, Políticas Públicas Educacionais e Formação de Professores. Rio de Janeiro/RJ - Brasil. sabrina.guedes@gmail.com

Resumo: Este artigo tem a finalidade de discutir as práticas pedagógicas dos professores da Rede Municipal de Ensino, a partir das relevantes experiências profissionais que traduzem os nossos momentos, olhares e percepções referentes à nossa atuação como formadoras/capacitadoras destes profissionais. Traremos para o debate o "lócus" da formação em serviço e sua relação com o "lócus" da atuação docente, espaço onde as práticas docentes acontecem. Nosso objetivo é traduzir a qualidade das formações em serviço - que são formações institucionais -, através do nosso papel, da nossa atuação. O nosso estudo abordará estes espaços de formação, suas instituições locais e os processos instituintes, de autoria e autoridade que acontecem. As tensões, os avanços e retrocessos que cotidianamente se sucedem. Este esboço atravessará as diferentes concepções de aprendizagem, filosofias e abordagens teóricas circundantes na atualidade e que são representativas do corpo profissional. Essa discussão se faz necessária quando falamos de formação em serviço.

Palavras-chave: Práticas Pedagógicas. Formação. Concepções de Aprendizagem

Abstract: This article aims to discuss the pedagogical practices of teachers of the Municipal Education Network, from the relevant professional experiences that translate our moments, looks and perceptions regarding our role as trainers of these professionals. We will bring to the debate the "locus" of in-service training and its relationship with the "locus" of teaching performance, where teaching practices take place. Our goal is to translate the quality of in-service training - which is institutional training - through our role, our performance. Our study will address these spaces of formation, their local institutions and the instituting processes of authorship and authority that take place. The daily tensions, advances and setbacks that follow one another. This outline will go through the different learning conceptions, philosophies and theoretical approaches that are presently representative of the professional body. This discussion is necessary when we talk about in-service training.

Key-words: Pedagogical Practices. Formation. Learning Concepts

\section{Introdução}

$\mathrm{P}$

ensar o professor, o seu exercício docente imbuído de elementos que o identificam e dizem o que de fato representa, enquanto detentor da significação pedagógica, é afirmar que é o sujeito que propicia, articula e compartilha com os alunos um contexto de significados.

Os primeiros movimentos de formação (inicial e posteriormente permanente), antes mesmo da sua entrada e participação enquanto estudante da área, retratam a importância da escuta, dos sentidos, dos 
olhares, das vozes, dos pensamentos e da construção dialogal que construiu ao longo da existência; sendo ele, como qualquer outro indivíduo, um repositório de informações e saberes da humanidade, não passivo e mero receptor, mas partícipe de uma comunicação interlocutora.

A questão da formação [...] compreendida como um aspecto, uma faceta das políticas e diretrizes de valorização profissional do magistério, tem se mostrado através de diversas vozes, de diversos sentidos e perspectivas teóricas supostamente mais autorizadas (NASCIMENTO, 2003, p. 20).

Com efeito, a pesquisa-formação-docência busca movimentos de transformação individual e coletiva, a partir das experiências formativas tecidas na aproximação dialética entre prática, teoria e prática. Possibilitando a imersão de sujeitos que aprendem ao mesmo tempo em que ensinam e pesquisam, e pesquisam e ensinam enquanto aprendem. Há o estabelecimento entre a articulação da produção do saber científico e a produção do saber cotidiano - construindo ciência.

O educador formado dentro desta perspectiva é um referencial teórico, composto por um cabedal de teorias, de conceitos, de fatos, de narrativas, de fontes e métodos, estabelecendo múltiplas e complexas relações entre eles; além dele mesmo "beber" em fontes distintas, indo além do conhecimento tradicional, interessando-se por aquilo que é contado (relatos) pela memória, pelo documento, pela fotografia, incorporando a parte e o todo de cada expressão individual, assumindo o diferente e o heterogêneo, tendo em vista desvencilhar-se dos espaços de ritos dispensáveis, e de repetições e processos equivocados.

Ultrapassando as barreiras do corpo teórico oficial e que se constitui como o determinante das práticas docentes nos espaços educacionais, o professor, a partir do contexto em que atua e das relações que aí estão colocadas, vai constituindo sua identidade profissional. Ao mesmo tempo, essas questões vão lhes possibilitando uma leitura dos cenários por onde transita, podendo chegar a corroborar ou questionar as diretrizes institucionais. e essa identidade que o constitui permeia todas as suas ações, chegando a corroborar ou questionar as diretrizes institucionais.

O educador é mais do que voz e eco dos espaços instituintes e institucionalizados, é elemento produtor e transformador da cultura, da história e sociedade. "O homem é produtor de cultura, de ideias, de transformações, de vida". (DIAS, 2015, p.29) Todo esse movimento vai se processando a cada fazer e a cada momento em que o professor pára para pensar que caminhos fez e que precisa refazer.

Quando estamos em processo de formação com os professores temos inicialmente contato com o seu discurso. Essa escuta, da parte do formador, precisa ser acolhedora e respeitosa. Além disso, os processos são individualizados, embora possamos nos ouvir e refletir em nossas trajetórias. Esse movimento 
faz com que também o formador resgate sua experiência docente e se coloque como um par, um parceiro que pode contribuir e receber contribuições.

\section{Desenvolvimento}

Falar de práticas docentes é também evocar os processos de formação deste mesmo profissional. Processo este, em serviço, que passa pela instituição e seu grupo de formadores. Embora, às vezes, tenhamos a impressão de que esse olhar sobre a formação não esteja tão claro em todos os momentos e espaços institucionais. Há por um lado uma sensação de solidão para alguns docentes e por outro a invisibilidade da escola como espaço de formação junto com seus pares e com os próprios alunos. Esse ainda é um aspecto que precisa ser dialogado com o professor: a escola é um local em sua prática se dá e que por isso, precisa ser um objeto de estudo para ele professor em diálogo com outras práticas que aí se colocam.

A própria formação (inicial e continuada) para a docência e, em consequência, a construção da sua identidade profissional vem sendo forjada a partir de ideologias convergentes com o sistema produtivo em vigor. É nesse contexto de formação que a reflexão acerca da docência e da construção da sua identidade profissional se faz necessária para compreendermos tanto os limites quanto as possibilidades que se colocam para uma educação que emancipe os sujeitos. Posto isto, entendemos que a construção da identidade docente ocorre a partir de diversos saberes. (ARRUDA et alli, 2015, p. 22744)

Enquanto formadoras docentes, nos desafiamos a olhar estas mesmas práticas que hoje são visíveis através dos nossos espaços de educação e seu corpo discente. Um momento de avaliação das propostas de formação, mas principalmente das concepções de educação, de aprendizagem que estamos imbuídos e que se entrelaçam com as políticas públicas que nos encorpam e nos fazem refletir sobre a trajetória da educação carioca. Não esquecendo que em boa parte dessas ações e políticas somos os representantes e nos colocamos enquanto agentes dessa política. Essa dimensão precisa também ser discutida com os pares docentes.

[...] uma identidade profissional se constrói, pois, a partir da significação social da profissão; da revisão constante dos significados sociais da profissão; da revisão das tradições. Mas também da reafirmação de práticas consagradas culturalmente e que permanecem significativas. (PIMENTA, 1996, p.76)

Colocar em debate esse assunto na atualidade é mexer com os espaços institucionalizados como a escola e as demais instâncias dos órgãos executores que nos dão a permissão para interferir, dialogar e permitir que o docente repense seu fazer pedagógico. Esse exercício se faz necessário ser incorporado a esse fazer para que possamos nos voltar para as demandas de cada tempo e espaço históricos, que por sua vez, indubitavelmente vão fortalecendo as práticas que aí se dão. Por isso, o exercício do olhar e da escuta sobre 
isso é importante para o processo que vai sendo construído e constituído. "É tão importante investir a pessoa e dar um estatuto ao saber da experiência" (NÓVOA, 1995, p. 25).

Não nos furtamos também da nossa condição de docentes e esse aspecto dialoga com a nossa própria formação que acontece com aqueles que nos dirigem, mas não foge da participação de par em par. "A formação de professores pode desempenhar um papel importante na configuração de uma nova personalidade docente" (NÓVOA, 1995, p. 24).

Pensando num processo formativo que acontece nos espaços de educação, podemos afirmar que a escola é esse pontapé inicial e que tem como representante, como próprio da função previamente estabelecida, o coordenador pedagógico.

Diante das inúmeras funções legais deste profissional, a formativa é inerente ao seu trabalho permitindo um aprofundamento da área de atuação docente.

se admitirmos que o movimento de profissionalização é, em grande parte, uma tentativa de renovar os fundamentos epistemológicos do ofício de professor, então devemos examinar seriamente a natureza desses fundamentos e extrair daí elementos que nos permitam entrar num processo reflexivo e crítico sobre nossas próprias práticas como formadores e como pesquisadores (TARDIF, 1999, p. 4).

O coordenador pedagógico é o profissional da sensibilidade no espaço educacional que fica na tensão entre o corpo docente e a gestão escolar, sem dissociar a sua participação e presença desse mesmo grupo. Isso é ser coordenador pedagógico, o ser, o elemento formador no espaço educacional.

Como ser formador? Como formar indivíduos que trazem na sua persona uma formação já instituída? Já construída? São questionamentos, indagações importantes e necessárias para pensarmos para qualquer sistema dirigente que cuida, prepara e forma professores já passados por uma formação inicial. Desafio instaurado.

O coordenador pedagógico tem papel fundamental na gestão dos processos escolares, sobretudo na formação de professores, e que o investimento na formação continuada dos docentes é um dos caminhos para a melhoria da qualidade da educação básica no país - o que exige também investimento na formação inicial e continuada do próprio coordenador. (PLACCO, 2012, p. 1)

Dentro de um sistema institucionalizado há uma legislação que carrega em si uma concepção político-educcacional que chega à gestão por meio de um ordenamento e decisório. Esse caminho traz um confronto pois mexe com a constituição e as próprias concepções do educador. E fica na responsabilidade do coordenador pedagógico a transmissão da voz que determina as ações determinantes.

Na Rede Municipal de Ensino do Rio de Janeiro, a função de coordenador pedagógico foi criada por meio da Lei Municipal no 2619 de 06 de janeiro de 1998, sendo uma das atribuições novamente confirmada a de formador.

Dentro da Unidade Escolar, os momentos legais e próprios de formação são denominados Centros de Estudos. São nesses momentos que o grupo de professores se reúnem entre sim e com o coordenador 
pedagógico para (re)avaliarem os trabalhos realizados, as questões a serem desenvolvidas na prática pedagógica, orientar a acompanhar as estratégias de ensino-aprendizagem, integrar o trabalho pedagógico às ações ocorridas no âmbito da Coordenadora e da Secretaria Municipal de Educação, fazer inferências a fim de promover a melhoria qualitativa no trabalho promovido, incentivos à docência-pesquisa. De acordo com Azanha (1983) cada escola tem características pedagógico-sociais irredutíveis quando se trata de buscar soluções para os problemas que vive. A realidade de cada escola é o único ponto de partida para um real e adequado esforço de melhoria.

Portanto, a figura do coordenador pedagógico é de fundamental articulação dentro do espaço de formação que é a escola. Outro ponto importante é que o coordenador pedagógico tem também o papel de articular os saberes do conjunto de profissionais, valorizando as práticas e possibilitando a articulação entre elas, o que pode gerar um desenvolvimento para todo o grupo de professores. Embora ainda percebamos que essa visão da escola como um espaço formador ainda necessita de mais investimento no sentido de fomentar os paradigmas necessário a essa idéia, pois alguns professores refutam esse paradigma. Então nos perguntamos: $\mathrm{O}$ que fazer quando isso acontece?

Quanto à dimensão formativa na atividade de coordenação pedagógica, todos [...] entendem que o coordenador pedagógico é o responsável pela formação continuada dos professores. (PLACCO, 2012, p. 5)

Um outro aspecto dessa formação é da possibilidade de visitar escolas, oportunizar formações fora da escola através de programas e projetos de outras instâncias e espaços. Como, por exemplo, o PNAIC (Programa Nacional de Alfabetização na Idade Certa).

A questão da formação docente é algo muito complexo, pois ela abrange espaços e pares diferenciados que dialogam com o professor/professora no percurso de todo o seu fazer. Esse percurso é marcado desde sua história de vida, formações iniciais, as concepções de ensinar, a escolha de metodologias, os recursos utilizados para a sua prática até ao próprio fazer cotidiano. Uma questão que observamos é o olhar distanciado do professor/professora sobre a escola como espaço de sua formação. Atrelada a essa situação o não reconhecimento de seus pares enquanto parcerias no trabalho de sua formação. Nesse sentido, o que precisa ficar claro é que o espaço da escola é um organismo de intensas tensões e intenções por sua própria natureza e que, para ser compreendido, faz-se necessário tomar essa natureza para descobrir seus caminhos coletivos para a superação de situações que precisam ser resolvidas, superadas e gestadas.

O professor deve buscar gradativamente uma continua formação. Esta busca não deve apenas ser uma exigência da escola ou do sistema em relação a cada professor, tampouco deve ser um 2 imperativo propagandistíco e esvaziado de significação crítica. Deve sim, ser elemento constitutivo dos próprios processos de formação do formador. Esse pode ser um procedimento capaz de garantir que cada professor, enquanto indivíduo/profissional e a escola, da qual seria elemento constituinte juntamente com outros indivíduos/profissionais, sejam habitados por essa postura formativa continuada. (CORDOVA, 2018, p.2-3)

Percebemos que esse processo de conscientização no que tange à formação ainda é um aspecto que necessita ser discutido. Como formadora de professores dos anos iniciais esse é um ponto que ainda necessitamos investir sobre o entendimento do professor/professora sobre isso. Nossas relações com 
outros professores/professoras também marcam nosso fazer e daí temos a possibilidade de nos reinventarmos na nossa prática.

Ao atuarmos como formadoras, percebemos como que um espelho que se reflete para ambas as identidades docentes: ao mesmo tempo que trabalhamos com o professor, essa relação retorna para o formador fazendo-o revisitar a sua própria prática de formação.

Esse trabalho nos possibilita compartilhar memórias, potencializar a escuta, busca fundamentar a escrita sobre a prática docente e desenvolve a leitura e o olhar sobre o universo docente. Essa identidade, que é inacabada, é marcada e atravessada por vários matizes da cultura escolar e assim encaminha para algumas direções que para construir pontes com as demandas que se apresentam no tempo e espaços compartilhados por alunos, professores, gestores e toda a comunidade.

Trabalhar com a formação do corpo docente é mexer numa identidade que está em processo e está sendo concebida permeada por várias instâncias, especialmente quando somos interpeladas a fazermos as vozes das políticas públicas em vigência, seja no espaço escolar ou mesmo não.

Bem sabemos que as estruturas e projetos formativos nem sempre respondem aos nossos perfis, necessidades ou paradigmas exatamente de acordo com o estágio de desenvolvimento profissional em que nos encontramos.

O grande desafio de ser formadora dentro de uma instituição pública e pertencer legitimamente a ela é isso, articular projetos e concepções polítco-pedagógicos que estimulem os professores e as professoras a repensarem seus posicionamentos, discutindo possibilidades de caminhos a serem tomados e investimentos em estudos que nos permitam ver além das barreiras que fazem parte das realidades que vivenciamos.

\section{Conclusão}

Este artigo foi gestado com as vozes e experiências de uma proposta de formação docente em serviço que trouxe o grande desafio de propor um projeto que fosse o diferencial em serviço à luz da nossa própria prática profissional.

É pensarmos num primeiro momento que antes de construirmos um trabalho formador, fomos formadas e pertencemos ao corpo docente que nos constitui e com ele tecemos as nossas práticas.

A qualidade, as tenses e os desdobramentos de uma prática formadora passam fundamentalmente por um projeto político pedagógico do qual estamos imersas e somos parte integrante e ideológica desse movimento que ultrapassa a dimensão do espaço escolar, mas se (re)faz no cotidiano.

Nesse processo revisitamos nossas práticas, refletimos sobre nossos paradigmas e conversamos com a realidade pedagógica e institucional de acordo com o espaço e o lugar e época que ocupamos. E é essa realidade épica que vai interferindo e nos fazendo interferir nos processos constitutivos que aí se dão: 
suas tensões, condições, ideologias, histórias de vida e leituras de mundo das mais simples às mais complexas, marcando essa enorme diversidade de formadores em si e entre si.

A cada tempo, as levas docentes que vão chegando com características novas em alguns quesitos e atravessadas pelas práticas e ethos docente historicamente colocados. Porém, o exercício e prática da formação se coloca no diálogo entre o que foi ou poderia ter sido com o que se apresenta para refletirmos sobre os caminhos possíveis desse fluxo ininterrupto.

Nesse sentido, entram em jogo também as reflexões sobre a direção das políticas públicas, suas limitações e suas possibilidades. Percebe-se assim que esse fazer tem uma identidade, pessoal, docente, institucional e que também está atrelada a constructos das demandas sociais e políticas de seu tempo.

A profissão docente então carrega muitas questões, algumas "velhas conhecidas" e outras como que disparadoras de "zonas de conforto" que nos empurram a conhecer o fazer que nos é peculiar. É uma profissão desafiadora que requer conhecimento e muita reflexão.

\section{Referências}

AZANHA, J. M. P. Documento preliminar para a reorientação das atividades da Secretaria. São Paulo: SEESP, 1983.

CORDOVA, Fabio; GRINGS, Venice. Formação Docente: um processo permanente. Disponível em < http://coral.ufsm.br/gpforma/2senafe/PDF/024e5.pdf> Acesso em 20 de set. 2018.

DIAS, Marcela. O Repertório Cultural do Professor: implicaçoes no processo de formação das criancas. Disponível em $<$ http://periodicos.pucminas.br/index.php/revistaich/article/view/11000/8796> Acesso em 28 de set. 2019.

NASCIMENTO, Cláudio Orlando C. O que querem os professores ante a formação continuada; itinerâncias, produção de sentidos e autorias nas narrativas docentes. Dissertação de mestrado. Salvador: Faced-UFBA, 2003.

NÓVOA, A. Vidas de Professores. 2. ed., Porto Editora, Porto, 1995. (Coleção Ciências da Educação).

PIMENTA, Selma Garrido. Formação de Professores - Saberes da Docência e Identidade do Professor. R.Fac.Educ. São Paulo, v.22, n2 p.72-89, jul./dez.1996.

PLACCO, Vera Maria Nigro de. O coordenador pedagógico: aportes à proposição de políticas públicas. Cad. Pesquisa. vol.42 nº.147 São Paulo, dez. 2012.

TARDIF, Maurice. Conferência proferida na Faculdade de Educação da Universidade Federal de Pelotas - RS, no dia 25 de outubro de 1999. Universidade Laval, Quebec, Canadá.

Recebido em: 07 abr. 2019 / Aprovado em: 03 dez. 2019

\section{Para referenciar este texto}

MACEDO, Mônica Ramos da Costa; OLIVEIRA, Sabrina Guedes de. Relações de identidade docente: teares e diálogos entre professores e formadores em seus percursos e espaços formativos. Cadernos de Pósgraduacão, São Paulo, v. 18, n. 2, p. 242-248, jul./dez. 2019. Disponível em:

$<$ https://doi.org/10.5585/cpg.v18n2.13461>. 